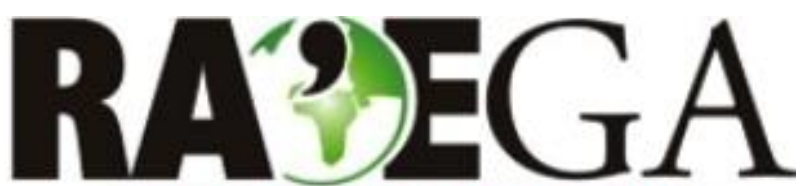

O ESPAÇO GEOGRÁFICO EM ANÁLISE

\title{
A MORADIA VERTICAL - UM ESTUDO SOBRE O PROCESSO DE APROPRIAÇÃO DA CASA E SEU ENTORNO SOCIOFÍ́SICO
}

\section{THE VERTICAL HOUSING- A STUDY ON THE PROCESS OF APPROPRIATION OF THE HOUSE AND ITS SOCIO-PHYSICAL ENVIRONMENT}

\section{RESUMO}

\author{
Alice Maccari ${ }^{1}$ e Teresinha Maria Gonçalves ${ }^{2}$
}

Este artigo apresenta os resultados de uma pesquisa sobre o ambiente urbano, realizada na cidade de Criciúma, Santa Catarina, Brasil - sob a perspectiva da Psicologia Ambiental, que serviu de base para a dissertação de mestrado em Ciências Ambientais da primeira autora. Trata-se de um estudo sobre a moradia vertical, em uma abordagem de pesquisa qualitativa, cujo método utilizado foi estudo de caso e a técnica de coleta de dados primários foi a entrevista semiestruturada. Os dados secundários foram buscados na prefeitura municipal de Criciúma (SC) e no Instituto Brasileiro de Geografia e Estatística, IBGE. O projeto de pesquisa foi aprovado na Plataforma Brasil, pelo Comitê de Ética para Pesquisa com Humanos. O coletivo amostral foi composto por 26 moradores residentes em prédios localizados em diversas ruas do bairro Comerciário, com tempo de moradia entre cinco a 16 anos. Os objetivos desta pesquisa foram verificar o processo de apropriação da casa e como se dão as relações sociais na vida coletiva dos moradores de edifícios, bem como analisar a percepção das pessoas em relação ao entorno sociofísico. O estudo demonstrou que a verticalização acaba por contribuir para a mudança de modos de vida e para o isolamento do indivíduo de seu convívio social, apesar de aparentar uma coletividade devido à proximidade das habitações. Os moradores entrevistados não têm vínculo social no bairro nem possuem envolvimento com os acontecimentos pertencentes à comunidade externa, atribuindo à sua vida social no bairro características que eles chamam de "reservada", "individualista", "praticamente nula" e "sem perturbações".

PALAVRAS-CHAVE: o processo de morar e habitar; convívio social; psicologia ambiental; relações de vizinhança.

\section{ABSTRACT}

This article presents the results of a research on the urban environment, from the perspective of Environmental Psychology, held in the city of Criciúma-SC Brazil, which served as the basis for the first Master's dissertation on Environmental Sciences. This is a study on vertical housing in a qualitative research approach whose method was the case study using as techniques of data collection the semi-structured interview. The secondary data were searched in the city hall of the city of Criciúma and IBGE. The research project was approved by the Education Committee for human research in the Brazil Platform. The sample collection consisted of 26 residents living in buildings located in several streets of the Comerciário district, with a residence time of 5 to 16 years. The objectives of this research were to verify the process of appropriation of the house and how the social relations of neighborhood are given in the collective life of the dwellers of buildings and to analyze the perception of the people in relation to the socio-physical environment. The study showed that verticalization contributes to the change of ways of life and to the isolation of the individual from his social life, despite appearing to be a community due to of the proximity of the dwellings. The residents interviewed don't have social link in the neighborhood nor they have any involvement with events belonging to the external community, attributing to their social life in the neighborhood characteristics that they call "reserved", "individualistic", "practically null" and "undisturbed".

KEY-WORDS: the process of living and dwelling; social interaction; Environmental Psychology; neighborhood relations.

Recebido em: 02/06/2016

Aceito em: 26/07/2017

\footnotetext{
1 Universidade do Extremo Sul Catarinense, UNESC, Criciuma/SC, e-mail: alicemaccari@hotmail.com

2 Universidade do Extremo Sul Catarinense, UNESC, Criciuma/SC, e-mail: tmg@unesc.net
} 


\section{INTRODUÇÃO}

Aqui se discute sobre a verticalização urbana como contexto para se compreender como as pessoas se sentem vivendo em moradias verticalizadas e como se configura o espaço público em um bairro onde a moradia é situada em edifícios. Que sentimentos esses espaços despertam na relação dos sujeitos com a sua casa e com o seu bairro e o que esse processo influencia no comportamento das pessoas, bem como se dá o processo de apropriação da casa e do bairro. Isso posto, esclarece-se que o objetivo do texto não é a discussão sobre a verticalização urbana em si. O que se pretende é demonstrar, por meio de pesquisa de campo, como se dá a apropriação da casa e do bairro em um espaço verticalizado.

A verticalização urbana, cada vez mais presente tanto em cidades médias quanto grandes, não leva apenas a uma mudança significativa na paisagem da cidade. As consequências dessa nova forma de morar costumam ir além, sendo capazes de causar transformações nos significados atribuídos ao espaço urbano, nos valores e, principalmente, nas relações interpessoais.

Ainda assim, percebemos que a verticalização de espaços dentro das cidades não é um processo realizado de forma democrática, visto que na produção do espaço urbano são muitos os agentes responsáveis por sua configuração, uns com mais poder do que os outros, os quais, na maioria das vezes, transformam esse espaço em produto, em uma mercadoria de valor, buscando lucros altos.

O cotidiano do espaço urbano, como corrobora Kanashiro (2003), está dominado pelas ideias de eficiência e funcionalidade em detrimento dos demais valores. A cidade, por consequência, passa a ser entendida como um "[...] emaranhado de problemas de ordem técnica e funcional, esquecendo-se dos valores pessoais, históricos e culturais, além da dimensão sensorial e psicológica das comunidades." (KANASHIRO, 2003, p. 163).

A expansão vertical se encontra em um acentuado processo de expansão no município de Criciúma, Santa Catarina, Brasil há aproximadamente duas décadas. Criciúma, que já teve o apogeu de sua economia na atividade carbonífera e ceramista, nos dias atuais, tem o capital imobiliário como grande propulsor do chamado desenvolvimento da cidade. O bairro Comerciário, localizado próximo ao centro da cidade, caracterizava-se, em um passado próximo, como um bairro bucólico, no qual se concentravam casas com jardins, quintais e hortas e algumas chácaras. Hoje possui como característica a grande quantidade de edifícios, em sua maioria residenciais. 0 espaço público do bairro, em termos de parques e praças, não existe, e as calçadas, consideradas espaços públicos, são muito precárias, inviabilizando a convivência comunitária e a própria apropriação do entorno dos edifícios.

A verticalização, que é considerada um marco revolucionário na paisagem urbana, surge nas cidades como uma nova ideologia, uma nova concepção de morar, estando associada, na maioria das vezes, a uma boa localização, infraestrutura e segurança.

Esse processo de expansão vertical observado na maioria das cidades do mundo e do Brasil antes era observado apenas em grandes metrópoles. Hoje já pode ser visto em pequenas e médias cidades, acompanhando o processo de expansão urbana horizontal, impulsionada principalmente pela ampliação do crédito imobiliário, o qual propiciou a sua expansão vertical (MORAIS; SILVA; MEDEIROS, 2007).

Os agentes imobiliários se apropriam e consomem o espaço urbano como se ele fosse uma mercadoria, não para a sua satisfação pessoal, mas para realizar seu desejo de lucro. Essa apropriação e esse consumo ocorrem de forma diferenciada, tendo em vista que os processos sociais, políticos, culturais e econômicos que comandam a estruturação/reestruturação do espaço urbano sempre se realizam de modo desigual.

É interessante destacar que a verticalização, enquanto um elemento do crescimento urbano, segundo Costa (2000), não deve ser vista como um problema por si só. Ela 
também é importante na medida em que atende às necessidades do modelo econômico e da sociedade em que vivemos, sendo vista como uma solução para os problemas espaciais, pois favorece a otimização do uso do solo por meio das construções verticais. O edifício vertical, construído de forma planejada, é um elemento importante na grande cidade, pois além de favorecer o desenvolvimento das funções pertinentes a cada centro urbano.

Para se compreender o processo de verticalização das cidades brasileiras, deve ser analisada a influência de cinco importantes fatores: a rápida e descontrolada urbanização devido ao processo de industrialização; a alta lucratividade do setor de venda de imóveis e especulação imobiliária; a falta de espaço nas localidades bem estruturadas dos centros urbanos; a ausência do governo no processo de urbanização e na responsabilidade de democratizar o meio urbano e o fascínio visual e tecnológico exercido pela concentração de edifícios no centro urbano (OLIVEIRA et al., 2015), tendo em vista os impactos positivos também proporcionados pelos edifícios altos, que estão associados à ideia de progresso, de modernidade, de desenvolvimento e de poder, ao impacto estético positivo na paisagem e à função do edifício alto como marco referencial, tanto de localização como de símbolo ou de ícone de uma cidade proporcionado pela verticalização (GREGOLETTO; REIS, 2012).

A verticalização, na visão de Ficher (1994 apud UEDA; CASTRO, 2013), representa, além das transformações já apresentadas na paisagem, uma modificação nos significados e nos valores associados ao espaço urbano e nas relações interpessoais, estabelecendo uma nova relação entre o homem e o espaço. Essas novas relações que se constroem, tanto interpessoais como aquelas entre o indivíduo ou os grupos e o seu espaço, acabam resultando em novas configurações do espaço físico, o qual vai se transformando para se adaptar a essas novas demandas.

Anthony Giddens (1991, p. 11) aponta que a modernidade "[...] refere-se a estilo, costume de vida ou organização social que emergiram na Europa a partir do século XVII, e que ulteriormente se tornaram mais ou menos mundiais em sua influência". Em sua obra, Modernidade e Identidade (2002), Giddens traz que a modernidade pode ser entendida como o equivalente ao mundo industrializado. Esse processo de constituição do urbano, vendo-o pela ótica do processo de urbanização, traz-nos um cenário de amplas e profundas transformações do espaço urbano e dos modos de vida urbano, o que inclui, naturalmente, as relações sociais. Elementos dos modos de vida e de formas de organização social sofrem uma transformação por meio da ciência e da técnica, que geram uma racionalidade instrumental, na perspectiva de Habermas (1990), a qual gere o mundo da vida. Habermas (1990) aponta uma outra racionalidade, a comunicativa, que deveria gerir esse mundo. Isso é muito importante para o entendimento da vida coletiva no espaço urbano, onde os sujeitos procuram construir a identidade urbana, dada pelos novos modos de vida que este mundo urbano exige.

Segundo Giddens (2002), a escolha de um estilo de vida nas condições da alta modernidade, a maioria das vezes não é uma escolha, mas uma imposição. Nesse sentido, o indivíduo abraça tal estilo não somente porque essa prática preenche necessidades utilitárias, mas porque dá forma material a uma narrativa de auto identidade. No decorrer do dia a dia de cada pessoa, cada pequena decisão tomada por ela acaba contribuindo para a formação de sua identidade. Sendo assim, a escolha de uma residência, de um bairro e até de uma determinada região da cidade, com a finalidade de moradia, remonta a essas questões de escolhas de cada um no contexto desse cenário apresentado por Giddens.

Os edifícios, segundo Frúgoli Junior (1995), tendem a articular-se em um universo de práticas e representações, que visam criar um espaço à parte na cidade, representando uma nítida seletividade social. Ainda, para esse autor, as estratégias de segurança desses espaços acabam transformando a experiência da vida 
pública na cidade, pois alteram os hábitos de circulação, as trajetórias e os movimentos relacionados ao uso cotidiano das ruas. Os padrões de interação pública seriam marcados cada vez mais pela tensão, discriminação e suspeita, transformando, de maneira geral, o espaço público abandonado à popularização e deterioração, sendo ele cada vez menos utilizado pelas classes de maior poder aquisitivo, que buscam locais privatizados para estabelecerem suas relações sociais básicas.

A moradia em espaços reduzidos, a restrição do contato COM A natureza, a convivência com o barulho, o fato de cumprir normas e regulamentos urbanos, a competitividade para sobrevivência financeira e a adoção de práticas de segurança são apenas algumas modificações que o ser humano teve que criar e suportar para viver como citadino (CARVALHO, 2008).

O que está ocorrendo é uma racionalização da vida urbana, com predominância de traços como mobilidade, fluxo, deslocamento, organicidade, funcionalidade. A realização dessas formas específicas de modernização urbana aprofunda, de modo geral, as diferenças sociais; deteriora o espaço público; privilegia a privatização; acentua as exclusões sociais; cria uma cidade apartada, restrita, apontando uma redução considerável da diversidade e da heterogeneidade dos espaços de interação social interclasses (FRÚGOLI JUNIOR, 1995).

Dentre as mudanças mais sentidas pelos citadinos, como o fato de ter que lidar com a fluidez e os contrastes típicos do ambiente urbano, o habitante da cidade criou para si uma estratégia de autodefesa, pela qual passou a reagir em seu novo habitat não com os sentimentos, mas com a razão, tornando-se indiferente a qualquer realidade individual adversa da sua ou, de maneira mais ampla, a quaisquer relações e reações alheias (CARVALHO, 2008).

\section{A CONTRIBUIÇÃO DA PSICOLOGIA AMBIENTAL} PARA A COMPREENSÃO DO AMBIENTE URBANO
A Psicologia Ambiental (PA) tem como objeto de estudo o homem em seu contexto físico e social, buscando, segundo Günther, Pinheiro e Guzzo (2006), as inter-relações entre o homem e o seu ambiente. Ela atribui importância às percepções, às avaliações e às atitudes, interessando-se pelos efeitos das condições do ambiente sobre o comportamento individual, tanto quanto o indivíduo percebe e atua em seu entorno. É uma forma de analisar as percepções, as atitudes e os comportamentos tanto de indivíduos quanto de comunidades em estreitas relações com o seu contexto físico e social.

As cidades são consideradas o ambiente construído que mais influencia o comportamento humano. Heimstra (1978) acrescenta que o indivíduo que vive na cidade fica exposto a uma série variada de características ambientais, a qual possibilita a ocorrência de alguns tipos de comportamento e restringe outros. Essa situação pode ser entendida pelo fato de os habitantes de uma cidade possuírem uma população geralmente heterogênea, diferenciando-se nas questões econômicas, educacionais e motivacionais. Além disso, muitas características do ambiente urbano acabam contribuindo para a insatisfação com relação à vida na cidade, os chamados problemas urbanos, tais como a alta densidade populacional, a falta de espaço, o crime, a violência, as habitações precárias, dentre outros fatores.

A interação entre a pessoa e o meio ambiente é inevitável, pois, como percebemos, o espaço físico circundante é o meio onde se assentam os espaços culturais, onde o indivíduo vive e constrói a sua subjetividade. A relação entre pessoa/sociedade/meio ambiente vem apresentada, na maioria das vezes, por uma dimensão vivenciada e simbólica, referida por meio de tratados sobre qualidade de vida, bemestar social e comunidade e também nos relativos à percepção e à valorização da paisagem.

Para Gonçalves (2007), o ambiente é considerado a vivência concreta do sujeito, no qual ele trabalha, constrói sua casa, faz sua 


\section{A MORADIA VERTICAL - UM ESTUDO SOBRE O PROCESSO DE APROPRIAÇÃO DA CASA E SEU ENTORNO SOCIOFÍ́SICO}

poética, constrói laços e apega-se àquele lugar, sentindo-se pertencente a ele; o espaço não significa apenas o meio físico circundante, vai além, assumindo uma dimensão sociocultural que o sujeito internaliza e representa. Esse simbolismo relacionado ao espaço aparece ligado ao sentimento de pertença, de apropriação do espaço como processo de identificação, um agente transformador, pois mediante a ação sobre o entorno, a pessoa e a comunidade transformam o espaço, deixam suas marcas e o incorporam a seus processos cognitivo e afetivo.

A Psicologia Ambiental, mesmo tendo, desde as primeiras formulações desse campo, a reciprocidade das inter-relações pessoaambiente, vê que a maioria dos temas de estudo diz respeito à influência do ambiente sobre as pessoas. Isso se deve, segundo Pinheiro (1997), ao fato de, na tradição psicológica, sempre ter havido muito maior atenção à ação do ambiente sobre a pessoa do que o contrário. Mas, especialmente a partir da década de 80 , também de forma a tentar responder aos anseios estabelecidos com relação aos problemas ambientais, a PA passa a considerar mais enfaticamente a ação das pessoas sobre os ambientes e a pessoa não mais reage apenas aos ambientes, como também os conforma e atua neles em função de planos, objetivos, intenções, preferências, expectativas etc.

A sociedade - e suas relações com a natureza - está em constante evolução: mudam os costumes das pessoas, as suas formas de pensar sobre as coisas e sobre o mundo. Alterase, assim, o mundo, que acaba se modelando de acordo com as novas necessidades dos presentes, novas relações entre os componentes e entre as paisagens, fazendo com que despontem novas paisagens em detrimento de outras que vão desaparecendo (PAULA; SILVA; GORAYEB, 2014).

Dentro da psicologia, o conceito de percepção é o mais amplo possível. A psicologia situaria nossas preocupações dentro do escopo da cognição: processo mental mediante o qual, a partir do interesse e da necessidade, estruturamos e organizamos nossa interface com a realidade e o mundo, selecionando as informações percebidas, armazenando-as e conferindo-Ihes significado (DEL RIO; OLIVEIRA, 1999).

Ribeiro (2004 apud SANTOS; PINTO, 2010) enfatiza a discussão em torno do conceito de percepção, afirmando que o ato de perceber não é um ato dependente apenas do ambiente em si, pois o que o indivíduo percebe nem sempre é o que o ambiente é, mas o que os seus sentidos apreendem a partir de seu filtro cultural. Dessa forma, a percepção envolve a vida social, isto é, os significados e os valores das coisas percebidas decorrem de nossa sociedade e do modo como nela as coisas e as pessoas recebem valor ou função, por isso os indivíduos sentem e percebem formas, totalidades estruturadas dotadas de significação diante da realidade vivenciada por eles.

O campo da psicologia da percepção, voltado para a interpretação da realidade, tem sua grande importância, pois, segundo Del Rio e Oliveira (1999), cada um de nós possui sua visão de mundo, que não pode ser objetiva e sim composta de um conjunto de realidades subjetivas - as imagens que formamos mentalmente sobre o mundo vivido. Os significados, sistemas de valores e interpretações dependem de uma série de fatores, sejam eles sociais ou inerentes ao próprio indivíduo. Cullen (1983), em seus escritos sobre a paisagem urbana, complementa que

[...] o homem tem em todos os momentos a percepção da sua posição relativa, sente a necessidade de se identificar com o local em que se encontra, e esse sentido de identificação, por outro lado, está ligado à percepção de todo o espaço circundante. (CULLEN, 1983, p.14).

O estudo da percepção ambiental é fundamental para que possamos compreender as relações entre o meio social e a natureza, expectativas, satisfações e insatisfações, julgamentos e condutas da sociedade. Cada indivíduo percebe, reage e responde diferentemente, sendo suas respostas ou 

SOCIOFÍ́SICO

manifestações resultantes das percepções, dos processos cognitivos, dos julgamentos e das expectativas de cada um (TORRES; OLIVEIRA, 2008).

Melazo (2005) acrescenta que a percepção ambiental deve ser entendida como um processo participativo que envolve uma série de fatores sensoriais e subjetivos; valores sociais, culturais e atitudes ambientais das comunidades residentes nas cidades em relação ao espaço natural e transformado.

O bairro Comerciário, localizado nas proximidades da área central do município de Criciúma, foi o bairro escolhido para ser o objeto do presente estudo. A opção por esse espaço se deu pelo fato de ele possuir uma intensa verticalização. A população atual de Criciúma, segundo a Estimativa da População do IBGE para 2016 é de 209.153, e a população do bairro

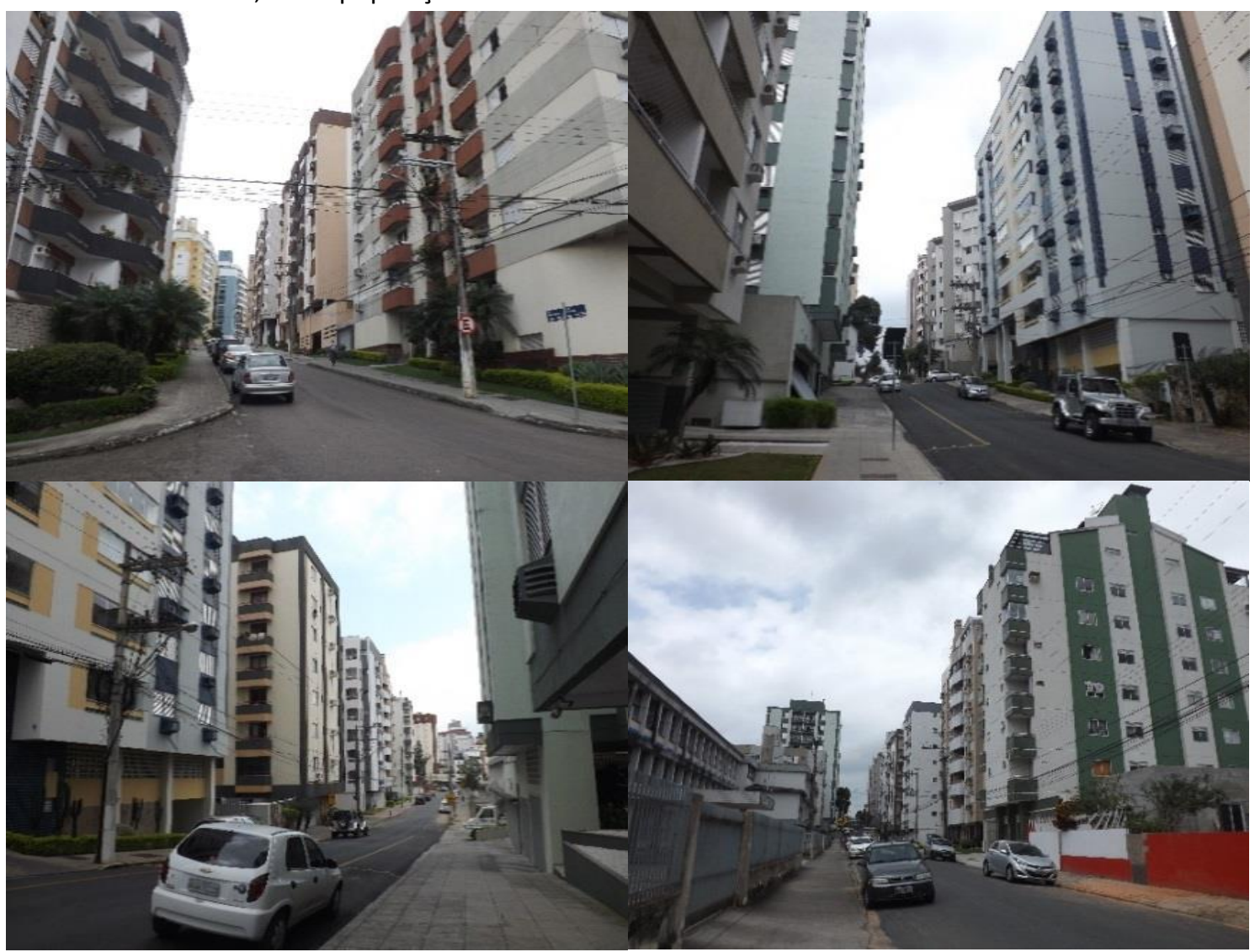

Figura 01 - Imagens de ruas do bairro Comerciário, as quais caracterizam a sua verticalização. Fonte: Acervo da autora (2015).

\section{DIRECIONAMENTO METODOLÓGICO}

A presente pesquisa possui como característica a natureza qualitativa e utiliza
Comerciário, segundo a mesma estimativa, é de 5.741 habitantes (IBGE, 2017).

A ocupação do bairro Comerciário, como mencionado, por si só não levaria a uma verticalização acelerada do local. Para tanto, leva-se em consideração um misto de fatores, dentre eles a proximidade com o centro, os terrenos mais baratos e o fato de o gabarito estabelecido pelo plano diretor ser um dos mais altos em relação à maioria das regiões de Criciúma, por não ter sido uma área minerada (NASCIMENTO, 2004).

A Figura 1 nos mostra o perfil de quatro ruas existentes no bairro Comerciário, possibilitando-nos perceber a grande quantidade de edifícios residenciais existentes na área. 


\section{A MORADIA VERTICAL - UM ESTUDO SOBRE O PROCESSO DE APROPRIAÇÃO DA CASA E SEU ENTORNO SOCIOFÍ́SICO}

tanto de documentação indireta - por realizar uma pesquisa bibliográfica - quanto por documentação direta - por se tratar de uma pesquisa de campo. 0 tipo de pesquisa de campo utilizada no estudo é o que possui como característica o caráter exploratório. A técnica de coleta de dados utilizada foi a entrevista semiestruturada.

Para a análise e interpretação dos dados coletados, que se constituem no núcleo central da pesquisa, foram utilizadas duas operações distintas, mas estreitamente relacionadas, que são a análise e a interpretação dos dados. Para a elaboração da análise, recorreu-se à utilização de três níveis para a síntese: a interpretação, a explicação e a especificação. $\mathrm{Na}$ etapa de interpretação, utiliza-se o procedimento de ligação com a teoria e se definem as alternativas disponíveis de interpretação da realidade social.

Foi necessário conseguir a aprovação do Comitê de Ética para Pesquisa com Humanos na Plataforma Brasil. Para o desenvolvimento desta pesquisa, utilizou-se a aplicação da entrevista semiestruturada com um total de 26 moradores residentes em prédios localizados em diversas ruas do bairro Comerciário.

Houve uma fase de aproximação com os sujeitos entrevistados, sendo que, para compor a amostra, os membros participantes foram selecionados seguindo os seguintes critérios: ter mais de 18 anos, ser morador no bairro entre 5 e 16 anos, querer participar da pesquisa. Em seguida, a pesquisadora forneceu o Termo de Consentimento Livre e Esclarecido para cada entrevistado. Nesse documento, emitido pelo Comitê de Ética em Pesquisa, constavam, claramente, os objetivos do estudo e que os dados referentes à pessoa entrevistada seriam sigilosos e privados, sendo a participação na pesquisa de forma voluntária.

A representatividade e a validade da amostra ou corpus da pesquisa foram dadas considerando-se que a amostragem qualitativa implica na identificação de um estudo qualitativo, portanto, “[...] a identificação da melhor fonte daquilo que se procura, ou seja, a forma mais consistente e fidedigna onde se busca o dado. Isso significa que o pesquisador precisa decidir que sujeitos guardam mais propriedade para responder aquilo que se busca." (SOUTO; KORKISCHKO, 2012, p. 33).

Considerando que o estudo é qualitativo, foi necessário utilizar um recorte da área do bairro, o qual possui a maior concentração de prédios. Para tanto, como pode ser observado na Figura 2, os limites do bairro Comerciário estão representados pelo contorno em vermelho, e a área em que foram concentradas as entrevistas está representada em destaque colorido no mapa. A escolha dos entrevistados, portanto, respeitou essa divisão espacial dentro do bairro Comerciário. 

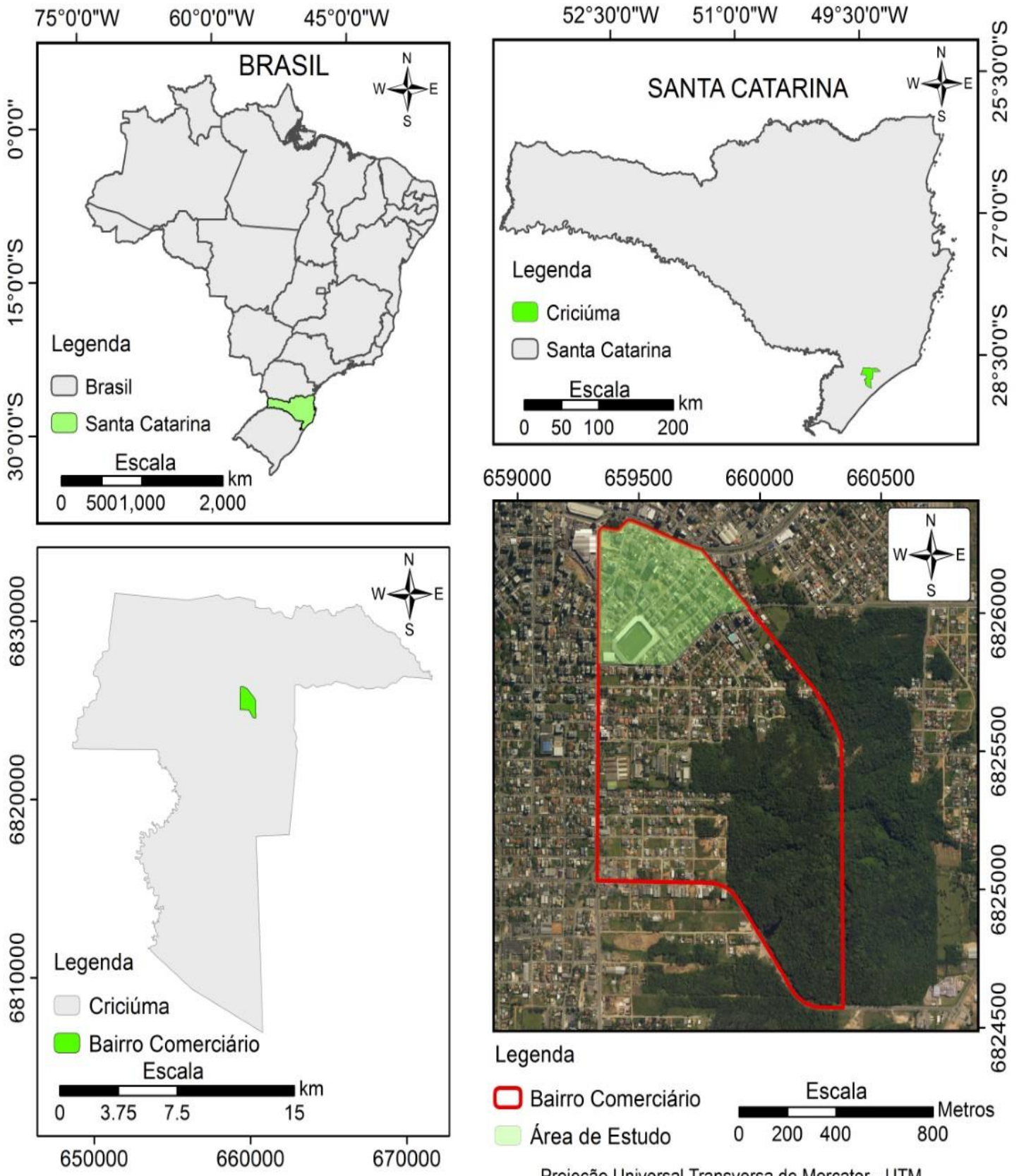

Legenda

Bairro Comerciário Área de Estudo

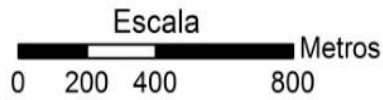

Projeção Universal Transversa de Mercator - UTM Meridiano de Referência $51^{\circ} \mathrm{W}$ - Fuso $22 \mathrm{~S}$ Datum Horizontal Sirgas 2000

Documentação: IBGE (2013) e SDS/SC (2011) Elaboração: CONTO, D. (2017)

Figura 02 - Representação do bairro Comerciário dentro do município de Criciúma, apresentando o recorte da área onde foram aplicadas as entrevistas Fonte: Acervo da autora (2015).

Para se ter uma ideia da abrangência espacial da pesquisa, a área onde foram realizadas as entrevistas, representada na Figura 2 em colorido, representa um total de 22,053 ha. É possível, ainda, estabelecer que dentro do perímetro do bairro Comerciário - que possui um total de 118,620 há -, existe a presença de uma área não edificada, representada pela área verde, correspondente ao Parque Natural Municipal Morro do Céu, o qual possui uma área de 46,38 ha. 


\section{A MORADIA VERTICAL - UM ESTUDO SOBRE O PROCESSO DE APROPRIAÇÃO DA CASA E SEU ENTORNO SOCIOFÍ́SICO}

\section{RESULTADOS E DISCUSSÃO}

Por meio das entrevistas realizadas com os 26 moradores do bairro Comerciário, foi possível caracterizar um perfil dos participantes desta pesquisa. A grande maioria dos moradores participantes, totalizando 17 entrevistados, possui idade entre 31 e 50 anos. Na sequência, segundo o critério de divisão por idades estabelecido para a pesquisa, três entrevistados com idade entre 18 e 30 anos e outros seis moradores participantes com idade acima de 51 anos. Ao se considerar o grau de instrução dos entrevistados, foi possível perceber que 20 deles possuem nível de Ensino Superior completo. 0 tempo de moradia no bairro varia de cinco a 16 anos.

Questionados sobre gostarem ou não do bairro onde moram, os entrevistados foram unânimes e responderam que sim. Ficou aparente em suas respostas que os motivos para gostarem de morar no bairro ficam em torno da proximidade que ele proporciona ao acesso de serviços urbanos e da sua tranquilidade, como pode ser percebido em alguns depoimentos dos moradores: "Por ser um bairro calmo e bem localizado."; "Porque é tranquilo e próximo a tudo."; "Pela tranquilidade do bairro, comodidade, proximidade de estabelecimentos, serviços."; "Proximidade com as prioridades escola, centro, hospitais, etc."; "Localização proximidade do local de trabalho e privilegiada por ter tudo que preciso próximo."; "Por ser mais próximo ao centro e também pela tranquilidade.". Para complementar essa questão, todos os entrevistados nesta pesquisa consideraram a sua vida no bairro boa ou ótima, deixando claro o apreço pelo bairro escolhido para moradia.

Aos entrevistados também foi solicitado descrever como é morar em apartamento. Segundo os relatos, esse estilo de moradia vertical ainda fica associado às questões de segurança e praticidade: "Tem praticidade em relação ao ambiente, proximidade de cômodos e uma maior segurança."; "Maior privacidade e segurança. Não tem relação com o vizinho."; "É prático morar em apartamento, porém o contato pessoal com os vizinhos desaparece."; "Sente-se aprisionado, mas é prático."; "Viver engaiolada."; "É seguro, organizado e de fácil manutenção de limpeza."; "É seguro, pouco contato com vizinhos, é necessário cuidado com as normas do condomínio."; "É seguro, mas nos priva muito de contatos com vizinhos e pouco contato com o sol."; "É prático e mais seguro, considerando que fico pouco tempo em casa. E também por não haver a necessidade de manejo com o ambiente externo."; "É entrar e fechar a porta, não há preocupações com quintal e há privacidade.".

Para Nazário (2009), quando as pessoas residem em casas, elas possuem uma probabilidade maior de se relacionarem com os vizinhos e com a natureza, pois há a opção de manter jardins, quintais floridos, um maior contato com a rua e com o seu entorno. Devido a isso, as residências unifamiliares trazem um maior sentido de pertencimento aos seus moradores, o que não se observa nas residências plurifamiliares, pois esse relacionamento natural e humano não é visto pelos moradores.

De fato, a moradia em edifícios afasta as pessoas umas das outras, no sentido de relacionamento entre elas, mesmo morando tão próximas. Os moradores dos edifícios não têm vínculo social no bairro nem possuem envolvimento algum com os acontecimentos pertencentes ao seu local de moradia ("Muito pouco contato com a comunidade."; "Não convivo com quaisquer pessoas do bairro."; "Pouco contato com os moradores."), atribuindo à sua vida social no bairro características que eles chamam de "reservada", "individualista", "praticamente nula" e "sem perturbações".

Até mesmo no relacionamento com os vizinhos, ali tão próximos, muitas vezes porta a porta, é possível perceber certo acanhamento. Quando questionados sobre o relacionamento com os vizinhos, foi fácil perceber a falta de envolvimento com relação às relações de vizinhança: "Praticamente sem contato."; "Meramente cordial."; "Cordial e respeitosa."; "Me relaciono com poucos no prédio, mas é uma 
boa relação."; "Não tenho muito contato, mas é amigável, gentil."; "Tranquila, não se tem muita amizade."; "Boa convivência."; "Não existe, só nos cumprimentamos."; "Pouca. Troco palavras apenas quando encontro no elevador."; "São boas, no geral.".

Diante dos relatos dos moradores quanto à relação com os vizinhos, percebe-se que, em geral, as relações são boas, mas porque realmente são superficiais. As relações com os vizinhos são resumidas em ações de cordialidade, educação, respeito, sem algum contato mais profundo de afinidade, companheirismo, preocupação com o seu vizinho.

As contribuições de Nazário (2009) nos apontam que quando se escolhe o modo de vida baseado em uma moradia vertical, acaba-se aderindo a uma vida privada baseada no individualismo, não porque os sujeitos ali residentes têm menos sensibilidade ou desejam menos interações que os demais, mas porque já moram em apartamentos devido ao tempo reduzido para esse tipo de atividade, seja ela de socialização com o próximo ou de reflexão e aprimoramento de si mesmo enquanto pessoa. Quando se compara essa relação entre moradores de casa e moradores de edifícios, percebe-se que é mais difícil o desenvolvimento afetivo entre os moradores de prédios.

As pessoas são seres sociais e gostam sim da companhia dos seus semelhantes, mas como elas toleram ou apreciam a proximidade física de outras pessoas, por quanto tempo e em que condições, isso varia sensivelmente de uma cultura para outra (TUAN, 1983).

As vantagens de se morar em edifícios, segundo os entrevistados, resumem-se, novamente, ao fato desse ambiente proporcionar uma maior segurança. Com relação às desvantagens desse tipo de moradia, percebe-se que os usuários sentem, repetidamente, falta de espaço aberto, de um contato maior com a natureza, com áreas abertas, e também de se relacionar com os vizinhos: "Não tem contato com a natureza."; "Fica muito trancado, diminui o contato interpessoal com os vizinhos."; "Falta de privacidade, falta de espaço aberto e pouco contato com a natureza."; "Não ter um local com área verde."; "Vemos pouco os vizinhos, falta de pátio."; "Espaço limitado."; "Isolamento, pouco sol, espaço para lavar roupa, secar."; "Engaiolamento, falta de contato com áreas verdes, falta de privacidade com relação aos vizinhos, barulho dos vizinhos."

Quanto mais individual a moradia, mais ela serve para afastar as pessoas umas das outras, gerando uma quantidade de estranhos a andar pelas ruas cada vez maiores. Opta-se por apartamentos porque eles são "mais seguros", mas, ao se individualizar a convivência entre as pessoas, poucas irão perceber quem é seu vizinho de porta, de andar ou de prédio, criando um efeito contrário ao esperado, porque também os marginais já perceberam que é exatamente nesses lugares que as pessoas pouco se preocupam umas com as outras. Ocorre, assim, uma falha no sistema e as ruas de cidades eminentemente industriais, cada vez mais verticalizadas, possuem cada vez menos segurança, tornando-se ruas de ninguém (NAZÁRIO, 2009).

Carlos (2004) acrescenta que os edifícios de apartamentos dificultam sim a aproximação entre as pessoas. À medida que a cidade se reproduziu, a vida dos moradores também deixou de ter o tempo e os lugares para vivenciar atividades recreativas. Os lugares de encontro desapareceram, as rodas de conversa não mais existem, o fervor das conversas e "burburinhos" calaram-se, as brincadeiras infantis no meio das ruas diminuíram, os espaços foram transformados em mercadorias, saindo de cena as praças, as árvores, e tomando o seu espaço mais uma nova construção.

A vivência é cada vez menor no espaço da cidade. Como complementa Gomes (2002), o uso da via pública nas cidades atuais se restringe progressivamente ao seu valor instrumental primário, à circulação. Saímos cada vez menos e quando o fazemos, em geral por absoluta necessidade, devemos usar automóvel, que nos levará a um lugar preciso, onde, habitualmente, reproduz-se a ideia de confinamento e de segurança. 
Esse isolamento da população traz um problema ainda maior para as cidades, pois cada vez mais as pessoas evitam tomar as ruas, preocupar-se com o seu entorno, caminhar pelas calçadas do seu bairro. Foi possível observar que nem todos os moradores entrevistados possuem o hábito de caminhar pelas calçadas do seu bairro, em uma forma de habitar verdadeiramente a rua. E dentre os que possuem esse hábito, a calçada serve apenas como um espaço de locomoção, sendo utilizada quando o motivo é uma obrigação, ou quando se tem que ir a algum lugar. Não se percebe a adoção do uso desse espaço como um hábito de conhecer melhor as ruas, as pessoas, o próprio bairro.

Segundo Menegat (2008 apud NAZÁRIO, 2009), morar em prédio significa, nos dias de hoje, que as portas permanecem fechadas e cada qual vive para dentro e não mais para fora. São avenidas congestionadas, ar poluído e os sujeitos dentro desse sistema, mergulhados nos problemas diários e com tantas paredes de concreto, tanta informação, tanta velocidade a Ihes atrair a visão, que eles deixam de olhar ao seu redor para apenas seguir o ritmo. Desse modo, o indivíduo encontra-se completamente capturado pelo sistema urbano dilacerador de nossa capacidade de transcendência humana, que nos rouba a capacidade de percepção da totalidade da paisagem. Esse homem já não consegue mais ver o entorno e não o vendo não consegue mais senti-lo, apreendê-lo como parte de sua realidade eminentemente humana.

Como complementa Gonçalves (2007), essa cultura acaba fazendo com que os moradores da cidade imaginem que a rua é o lugar de todos os perigos, e ao mesmo tempo os usuários de edifícios povoados em andares superiores permanecem num domínio misterioso e desconhecido, com exceção daqueles - amigos ou conhecidos - que são frequentados.

Reforça-se, nesse sentido, o potencial para uma cidade segura quando mais pessoas se movimentam pela cidade e permanecem nos espaços urbanos. Uma cidade que convida as pessoas a caminhar, por definição, deve ter uma estrutura razoavelmente coesa que permita curtas distâncias a pé, espaços públicos atrativos e uma variedade de funções urbanas. Esses elementos aumentam a atividade e o sentimento de segurança dentro e em volta dos espaços urbanos. Há mais olhos nas ruas e um incentivo maior para acompanhar os acontecimentos da cidade, a partir das habitações e edifícios do entorno (GEHL, 2013).

\section{CONSIDERAÇÕES FINAIS}

A opção da humanidade de habitar coletivamente fez com que a cidade se enobrecesse ao possibilitar aos seus habitantes várias vantagens, como o acesso à habitação, emprego, abastecimento, saneamento, energia, educação, saúde, transporte e lazer.

Por outro lado, a moradia vertical também compromete as relações sociais, e este afastamento dos vínculos entre as pessoas não se restringe apenas aos vizinhos de porta do mesmo edifício. Os moradores de edifícios preferem não ser incomodados nem se importam, muitas vezes, com o que ocorre do lado de fora do seu apartamento, tendendo, cada vez mais, ao isolamento dos acontecimentos da cidade.

Em pleno século XXI, vive-se em um tempo social onde as pessoas sequer conhecem os seus próprios vizinhos, onde os vínculos sociais são extremamente reduzidos em função do tempo que sempre corre contra eles especialmente na cidade. As relações estabelecidas com o outro, no ambiente citadino, não fazem parte da vivência cotidiana dos moradores, inclusive os espaços importantes atribuídos para as trocas de experiências, como as praças, as ruas $\mathrm{e}$ os parques. $\mathrm{O}$ empobrecimento dos vínculos afetivos, familiares e socioculturais tornam-se hábitos comuns que persistem gravemente no ambiente da cidade, transformando-a em uma representação fria, desencantada e que pouco tem a ver com os seus habitantes.

As cidades cresceram e se transformaram em estruturas tão complexas e difíceis de administrar, que quase não nos lembramos de que elas existiam, primeiramente 
e acima de tudo, para satisfazer as necessidades humanas e sociais das comunidades.

De fato, geralmente, as cidades não conseguem ser vistas sob essa ótica. Quando questionadas sobre as cidades, provavelmente as pessoas irão falar de edifícios e de carros, em vez de falarem de ruas e praças. Se perguntadas sobre a vida na cidade, falarão mais do distanciamento, do isolamento, do medo da violência ou do congestionamento e da poluição do que de comunidade, participação, animação, beleza e prazer.

As relações comunitárias foram sendo abandonadas à medida em que as cidades foram se desenvolvendo e se expandindo junto com o comércio e com o mercado, pautando-se nos princípios reguladores impessoais das urbes. Os valores atribuídos aos citadinos baseiam-se em interesses individuais e na competição, inclusive na busca pelo lucro a qualquer preço (CARVALHO, 2008).

Pode-se concluir, segundo Sennett (2002) que assistimos ao que acontece nesta era da velocidade com certa impotência. Parece não haver espaço para a convivência, para o contato com o heterogêneo urbano. Considera-se como perda de tempo, como algo negativo e potencialmente perigoso o contato com o outro. Por sua vez, a impessoalidade é imposta para a manutenção da privacidade e da vida íntima e familiar dos habitantes da cidade.

No mundo desenvolvido, esse conflito está levando os cidadãos a se enclausurarem em territórios particulares protegidos, segregando ricos e pobres e acabando com o verdadeiro significado do conceito de cidadania. O autor ainda acrescenta que as cidades só podem refletir os valores, os compromissos e as resoluções da sociedade que elas abrigam; como consequência, o sucesso de uma cidade vai depender de seus habitantes e do poder público, além da prioridade que ambos dão à criação e à manutenção de um ambiente urbano e humano.

A construção de uma cidade sadia, do ponto de vista socioambiental, realmente será efetiva quando for eliminado o anonimato, a exclusão social, o distanciamento existente no relacionamento entre os habitantes da cidade e, ainda, a compreensão por parte dos habitantes de que a sua própria sobrevivência e a sua identidade estão estritamente relacionadas ao território do qual são parte integrante.

\section{REFERÊNCIAS}

CARLOS, A.F. O Espaço Urbano: Novos escritos sobre a cidade. São Paulo: Contexto, 2004.

CARVALHO, V. S. Educação Ambiental urbana. Rio de Janeiro: Wak Ed., 2008.

COSTA, A. A. da. A verticalização de Natal: elemento de transformações sócio-espaciais. In: Seminário de História da Cidade e do Urbanismo, 6., 2000, Natal, Anais... . Natal: UFRN, 2000, p. 1$15 . \quad$ Disponível em: <http://unuhospedagem.com.br/revista/rbeur/in dex.php/shcu/article/view/756/731>. Acesso em: 23 dez. 2015.

CULLEN, G. Paisagem Urbana. Lisboa: Edições 70, 1983.

DEL RIO, V.; OLIVEIRA, L. Percepção Ambiental: a experiência brasileira. 2. ed. São Paulo: Studio Nobel, 1999.

FRÚGOLI JUNIOR, H. São Paulo: espaços públicos e interação social. São Paulo: Marco Zero, 1995.

GEHL, J. Cidades para pessoas. 2. ed. São Paulo: Perspectiva, 2013.

GIDDENS, A. As Consequências da Modernidade. São Paulo: UNESP, 1991.

GIDDENS, A. Modernidade e Identidade. Rio de Janeiro: Jorge Zahar, 2002.

GOMES, P. C. C. A condição urbana: ensaios de geopolítica da cidade. Rio de Janeiro: Bertrand Brasil, 2002

GONÇALVES, T. M. Cidade e poética: um estudo de psicologia ambiental sobre o ambiente urbano. Ijuí: Unijuí, 2007.

GREGOLETTO, D.; REIS, A. T. da L. Os edifícios altos na percepção dos usuários do espaço urbano. Cadernos PROARQ, n. 19, p. 89-110, $2012 . \quad$ Disponível em: <http://www.proarq.fau.ufrj.br/revista/public/do cs/Proarq19_OsEdificiosAltos_GregolettoReis.pdf >. Acesso em: 14 dez. 2015.

GÜNTHER, H.; PINHEIRO, J. Q.; GUZZO, R. S. L. Psicologia Ambiental: entendendo as relações do 


\section{A MORADIA VERTICAL - UM ESTUDO SOBRE O PROCESSO DE APROPRIAÇÃO DA CASA E SEU ENTORNO SOCIOFÍ́SICO}

homem com seu ambiente. 2. ed. Campinas: Alínea, 2006.

HABERMAS, J. O pensamento Pós Metafísico. Rio de Janeiro: Tempo Brasileiro, 1990.

HEIMSTRA, N. W. Psicologia ambiental. São Paulo: EPU, 1978.

IBGE, INSTITUTO BRASILEIRO DE GEOGRAFIA E ESTATÍSTICA. Criciúma: estimativa da população 2016. 2017. Disponível em: <http://www.cidades.ibge.gov.br/xtras/perfil.php ?lang=\&codmun=420460 \&search=santacatarina|criciuma>. Acesso em: 15 jul. 2017.

KANASHIRO, M. A cidade e os sentidos: sentir a cidade. In: FLORIANI, D.; HEEMANN, A. Desenvolvimento e Meio Ambiente: diálogo de saberes e percepção ambiental. Curitiba, UFPR, 2003, p.159-164.

MELAZO, G. C. Percepção Ambiental e Educação Ambiental: uma reflexão sobre as relações interpessoais e ambientais no espaço urbano. Olhares \& Trilhas, Uberlândia, v. 5, n. 6, p. 45-51, 2005.

MORAIS, L. S.; SILVA, P. C. M. da; MEDEIROS, W. D. de A. Análise do processo de verticalização na área urbana do município de Mossoró - RN: aspectos jurídicos e ambientais. Revista Verde, Paraíba, v. 2, n. 2, p. 171-182, 2007.

NASCIMENTO, D. do. Agricultura e mineração na formação do espaço urbano de Criciúma. In: GOULARTI FILHO, A. (Org.) Memória e cultura do carvão em Santa Catarina. Florianópolis: Cidade Futura, 2004, p. 383-392.

NAZÁRIO, T.G. O homem e seu entorno sociofísico: um estudo sobre o processo de morar e habitar de moradores de edifícios residenciais na cidade de Criciúma-SC. 2009. $260 \mathrm{f}$. Dissertação (Mestrado) - Programa de Pósgraduação em Ciências Ambientais, Universidade do Extremo Sul Catarinense, Criciúma, 2009.

OLIVEIRA, V. H. de et al. Verticalização consciente: edificar integrando ao meio urbano. REINPEC - Revista Interdisciplinar Pensamento Científico, Itaperuna, v. 1, n. 1, p. 13-29, 2015. Disponível em: <http://reinpec.srvroot.com:8686/reinpec/index. php/reinpec/article/view/40/8>. Acesso em: 03 dez. 2015.
PAULA, E. M. S. de; SILVA, E. V.; GORAYEB, A. Percepção ambiental e dinâmica geoecológica: premissas para o planejamento e gestão ambiental. Sociedade \& Natureza, Uberlândia, v.26, n.3, p. 511-518, set/dez 2014. Disponível em: <http://www.scielo.br/pdf/sn/v26n3/01031570-sn-26-3-0511.pdf>. Acesso em: 24 nov. 2015.

PINHEIRO, J. Q. Psicologia ambiental: a busca de um ambiente melhor. Estudos de psicologia, Natal, v. 2, n. 2, p. 377-398, 1997. Disponível em: <http://www.scielo.br/pdf/epsic/v2n2/a11v02n2 .pdf>. Acesso em: 20 nov. 2015.

SANTOS, C. O. dos; PINTO, J. E. S. de S. Percepção da qualidade socioambiental da área urbana de Itabaiana/SE. Mercator, Fortaleza, v. 9, n.18, p. 93-104, 2010. Disponível em: <http://www.mercator.ufc.br/index.php/mercato r/article/view/296/276>. Acesso em: 02 nov. 2015.

SENNETT, R. O declínio do homem público: as tiranias da intimidade. São Paulo: Companhia das Letras, 2002. 447p.

SOUTO, B. G. A., KORKISCHKO, N. Validação de pesquisa qualitativa por meio de descrição quantitativa da amostra. Revista Médica Minas Gerais, [s.I.], v. 22, n. 1, p. 31-38, 2012.

TORRES, D. de F.; OLIVEIRA, E. S. de. Percepção Ambiental: Instrumento para a educação ambiental em unidades de conservação. Revista Eletrônica do Mestrado em Educação Ambiental, Rio Grande, v. 21, jul/dez, 2008. Disponível em: $<$ https://www.seer.furg.br/remea/article/view/3 046/1725>. Acesso: 04 nov. 2015.

TUAN, Y. Espaço e Lugar: a perspectiva da experiência. São Paulo: DIFEL, 1983.

UEDA, G. S.; CASTRO, C. M. P. de. As dimensões simbólica e social na primeira etapa da verticalização em cidades brasileiras. In: Encontros Nacionais da Anpur, 15, 2013, Recife, Anais... .Recife: Anpur, 2013, p.1-17. Disponível em:

<http://unuhospedagem.com.br/revista/rbeur/in dex.php/anais/article/view/4508/4377>. Acesso em: 09 nov. 2015. 